\title{
ESTIMATION OF DOMINANT TREE HEIGHT IN FOREST STANDS USING LIDAR DATA
}

\author{
Andis Lazdins, Janis Ivanovs, Raitis Melniks \\ Latvian State Forest Research Institute "Silava", Latvia \\ raitis.melniks@silava.lv
}

\begin{abstract}
The aim of this study is to detect the dominant tree height in forest stands using LiDAR (Light detection and ranging) data. The dominant tree height is obtained from LiDAR data and that is compared with the forest inventory data from the State Forest Service (SFS). Results are analysed by dominant species, growth conditions and topography. Sample plots are selected randomly and the forest inventory data are obtained separately from LiDAR data and may cause some errors in terms of tree height. Data processing methods are outlined for detection of individual trees and terrain depressions. The average tree height from the LiDAR data is compared to that from the SFS database. The results show that the average height of a forest stand obtained from LiDAR is mostly up to 2 meters smaller comparing with the SFS database, depending on the dominant species and stand age. The most accurate results are obtained in forest stands with pine as a dominant tree species and in dry forest growth conditions. Comparison with trees growing in terrain depressions and outside them shows a significant difference. For more precise measurements in dynamics more LiDAR flights and higher point density are recommended.
\end{abstract}

Keywords: CHM, forest stand, individual tree, depression.

\section{Introduction}

Identification of individual trees using remote sensing data began at the end of the last century. Initially, passive data or aerial and satellite data were used, but due to insufficient resolution of the images, the possibilities for data acquisition and analysis were limited. With the advancement of technology, researchers started to use active data sources, LiDAR and radar technology [1]. The LiDAR technology is widely used in local forest inventory and combining with spectral information can distinguish individual trees even at a level of different species [2;3]. A research based on LiDAR data typically uses digital elevation models, digital surface models, and canopy height models. Individual tree detection using LiDAR data can be done in different ways. Popular methods are raster data processing, point cloud analysis, tree geometry reconstruction, and raster, point and raw data combination. The most popular method for individual tree detection is based on raster data analysis [4]. Digital elevation and surface models can be generated from laser scanning point clouds, which consist of several points per square meter [5]. LiDAR data, due to their high resolution, can be used to measure the horizontal and vertical structure of a forest stand. It is possible to measure a forest stand describing the parameters, such as the tree height, forest floor topography, forest stand biomass, number of trees and circumference of tree crown [6].

Given the fact that passive data dominated the data sources for individual tree detection studies before 2005, methods based on raster data have been used longer than other approaches. Traditional tree detection and obtaining algorithms (e.g., local maximum, region-growing, and watershed analysis) can be used on a canopy height model (CHM), which is extracted from the LiDAR point cloud, interpolated and smoothed [7]. In addition to CHM, researchers have also considered other LiDAR based products. Chen et al. [2] proposed the canopy maximum model (CMM) for eliminating the error caused by branches within crowns. CMM was successfully applied in subsequent studies [8]. Using most traditional approaches, tree detection is generally based on finding local maxima within the image, and crown delineation requires outlining minimum valleys and watershed segmentation [4]. These algorithms, which were initially developed for application to passive data, have undergone a range of improvement efforts in recent years $[6 ; 10]$.

Tree height and species composition may vary within individual forest stands due to soil wetness. A recent study evaluating the spatial distribution of wet mineral soils in forests in Latvia using LiDAR data gives a methodology for wet soil mapping [11]. In this study digital elevation model depressions and other indexes were used to detect wet soils and characterize tree growth conditions.

\section{Materials and methods}

The study area consists of 14 sample plots, $1 \mathrm{~km}^{2}$ each, containing 1352 forest stands in total. Fig. 1 shows the location of the sample plots. LiDAR data, which are necessary for digital elevation model 
(DEM), digital surface model (DSM) and CHM generation, are obtained from the Latvian Geospatial Information agency (LGIA). Average point cloud density in LiDAR point cloud datasets is between 4 and 14 points per square meter. Minimum ground point density should excess 1.5 points per square meter. Selected forest stands are measured with LiDAR sensor in \pm 1 calendar year compared to the version of the SFS database.

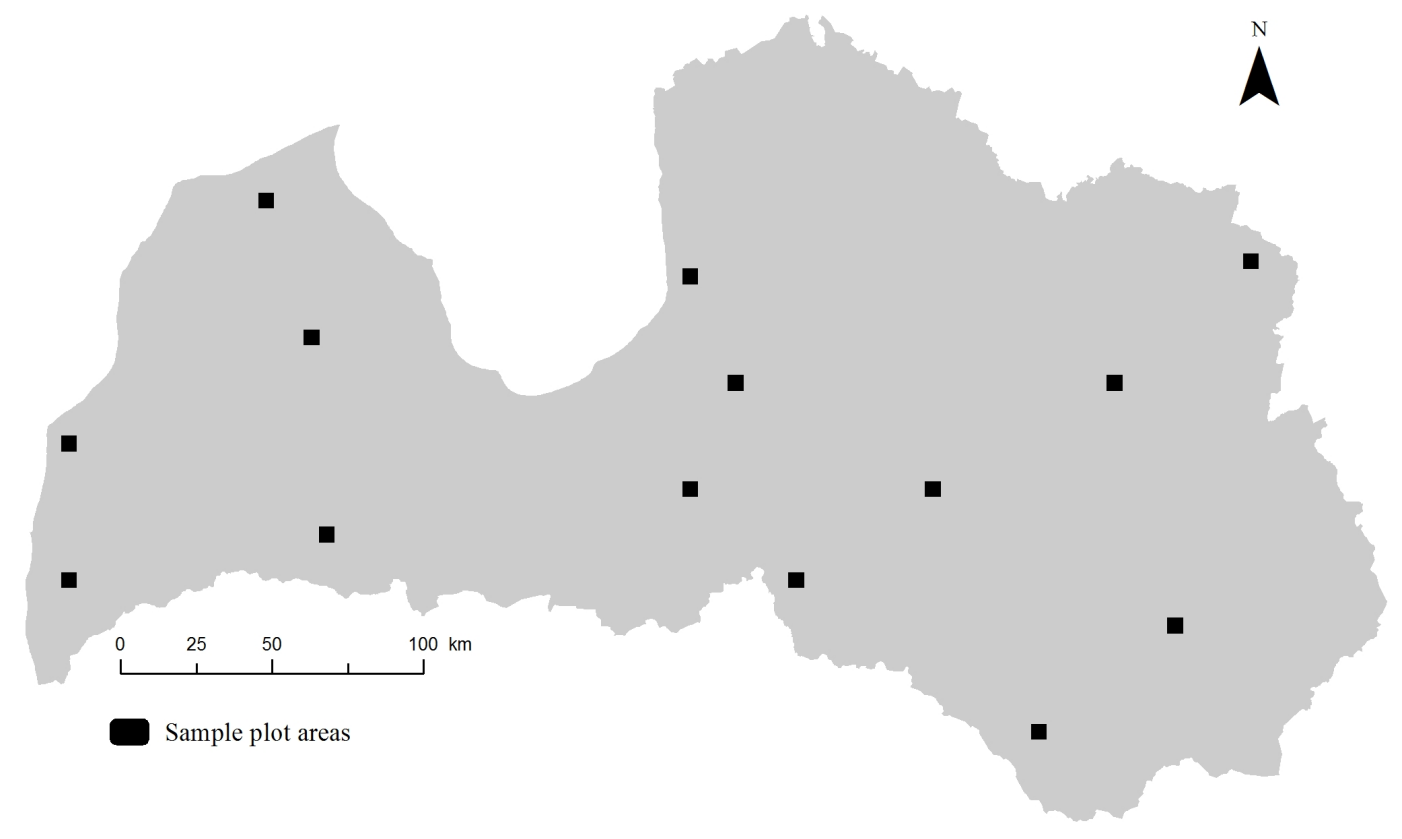

Fig. 1. Study sites

Data processing has been done in GRASS GIS 7.4. software. DEM is made in $2 \times 2 \mathrm{~m}$ resolution, DSM is made in $0.5 \times 0.5 \mathrm{~m}$ resolution. DEM is made in a coarser resolution, because terrain in Latvia is relatively flat and raster files made in coarser resolution require less processing resources without losing information about the properties of terrain. DSM is made as precise as possible for given density of the obtained LiDAR point cloud.

Local maximums in CHM are defined using the sliding window principle. Each cell is assigned a value that corresponds to the maximum value of CHM within 8 neighbouring cells. Since the size of the CHM raster cell is $0.5 \times 0.5 \mathrm{~m}$, the treetop must be at least 1.5 meters away from the other top of the tree to be identified in the new raster image as an individual tree. If a tree has more than one top, each top may be counted as a separate tree. For more precise outcome, LiDAR data with higher point density are required.

Locations of dominant trees are then obtained using equation (1). This formula finds centre points of previously generated local maximums. Since all peaks in local maximum raster now are represented as 9 cell squares with equal values, it is possible to locate central cells of those squares.

$$
\begin{gathered}
\operatorname{if}((X[-1,-1]==X[0,0] \& \&(X[-1,0]==X[0,0]) \& \&(X[-1,-1]==X[0,0]) \& \& \\
(X[0,-1])==X[0,0]) \& \&(X[0,1]==X[0,0] \& \&(X[1,-1]==X[0,0]) \& \& \\
(X[1,0]==X[0,0]) \& \&(X[1,1]==X[0,0]), X, \text { null }())
\end{gathered}
$$

where $X$ - raster of local maxima, numbers in square brackets are coordinates for neighbouring pixels;

operator $==$ means "logical equal";

operator \&\& means "logical and".

Further analysis is done to select local maximums that represent trees and not terrain peaks or other landscape elements. Definition of forest in Latvia determines that forest is an ecosystem in which the tree height can reach at least $5 \mathrm{~m}$ [13], so the cells with the CHM values below $5 \mathrm{~m}$ are filtered out by equation (2). 
where $X-\mathrm{CHM}$ raster map

Final raster map, which contains dominant trees and information about the tree height, is converted to polygon vector data format and for each polygon a centroid is added. Every point represents an individual tree and after that, v.vect.stats is used to intersect the obtained data of individual trees with polygons of forest stands from the SFS database.

Characterization of forest growth conditions based on depressions in topography is made using SAGA GIS algorithm Fill Sinks (Wang\&Liu) [12]. Fill sinks is an algorithm that is often used in hydrological modelling to discern the flow direction. Raster map of depressions is generated by extracting original DEM from filled DEM. Resulting raster map contains information about spatial distribution and depth of depressions in given area.

Depression raster map is converted to polygon vector data format using GRASS GIS tool r.contour to outline depressions which are at least $0.1 \mathrm{~m}$ deep. Vector data about depressions are used to split the previously generated dominant tree point layer into trees that are growing in depressions and outside them within separate forest stands.

\section{Results and discussion}

This section shows how the height of trees determined by analysis of LiDAR data compares to the SFS database. Fig. 2 shows a comparison of the height of dominant trees by the dominant species: (a) scots pine, (b) Norway spruce, (c) birch and (d) grey alder and black alder. It can be seen that the height is most accurately determined for the pine (average underestimation of $1.8 \mathrm{~m}, \mathrm{R}^{2}=0.7993$ ). This is due to the shape of the tree crown and the fact that this species is evergreen. The worst tree height determination is for deciduous trees (average underestimation of $1.9 \mathrm{~m}, \mathrm{R}^{2}=0,548$ and $\mathrm{R}^{2}=0.4872$ ). LiDAR data are obtained in a leaf-off period and the first reflection has little chance of being reflected from the tree top. The greatest inaccuracies can be observed on the lowest deciduous trees, because both the trunk and the branches are comparatively thinner and therefore more difficult to record in the remote sensing data.
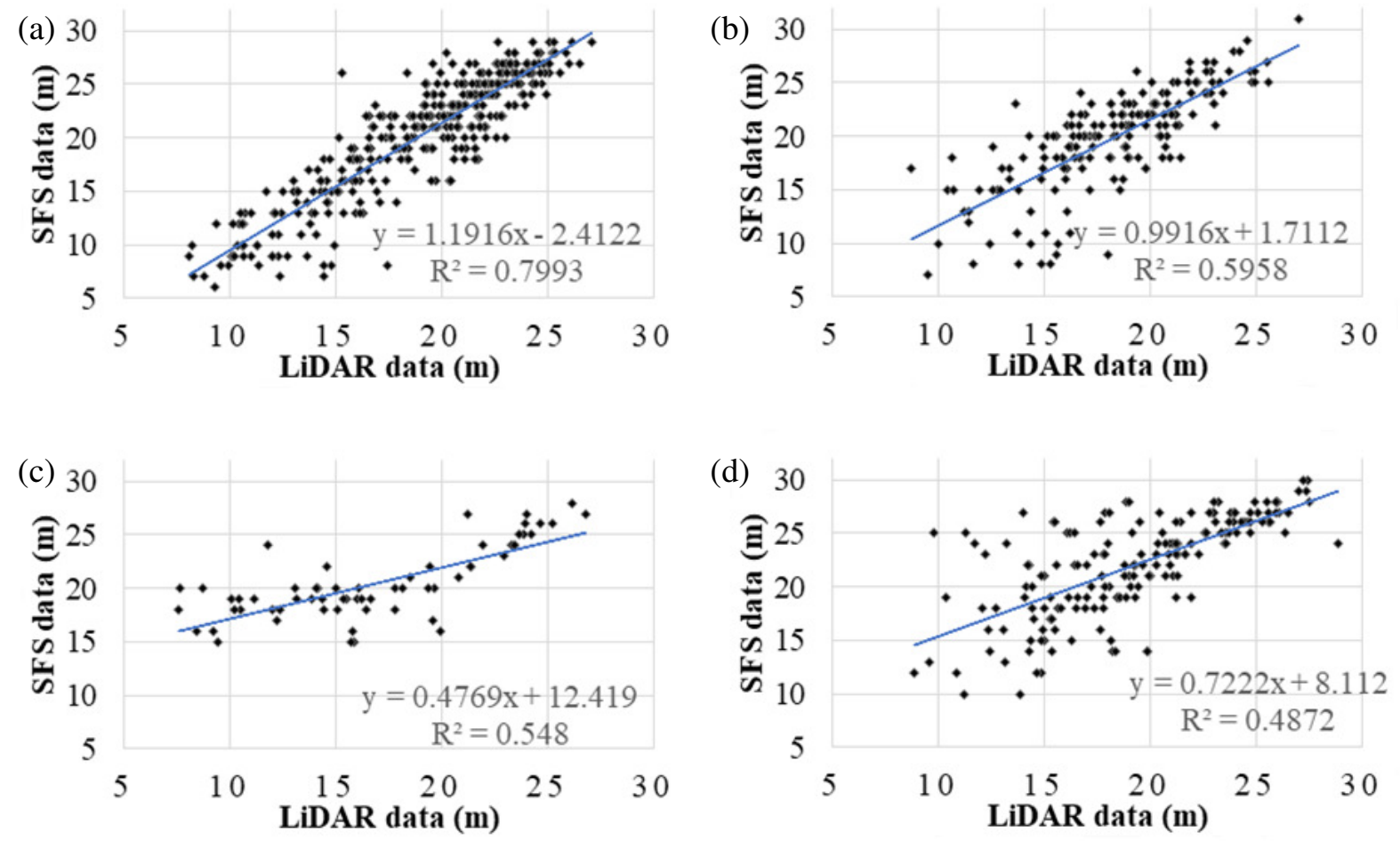

Fig. 2. Tree height comparison by species 
Tree height comparison between SFS and LiDAR data for different forest growth conditions is shown in Fig. 3. The figure shows a comparison of (a) forests on dry mineral soils, (b) forests on dry mineral soils, except Oxalidosa and Aegopodiosa, (c) forests on wet mineral soils, (d) forests on wet peatlands, (e) forests on drained mineral soils and (f) forests on drained peatlands. The best results are observed in forests on dry mineral soils, especially in less fertile forest types (average underestimation of $1.9 \mathrm{~m}, \mathrm{R}^{2}=0.7513$ ). The most inaccurate measurements in the LiDAR data, on the other hand, are in wet forests on peatlands (average underestimation of $1.95 \mathrm{~m}, \mathrm{R}^{2}=0.3452$ ). There is a coincidence that in forests on drained mineral soils and drained peatlands the determination of the tree height in remote sensing data is better than in forests on wet mineral soils and wet peatlands. It can be concluded that in forests on drained soils the tree growing conditions have improved and the forest stands become more homogeneous, hence LiDAR measurements are more accurate.
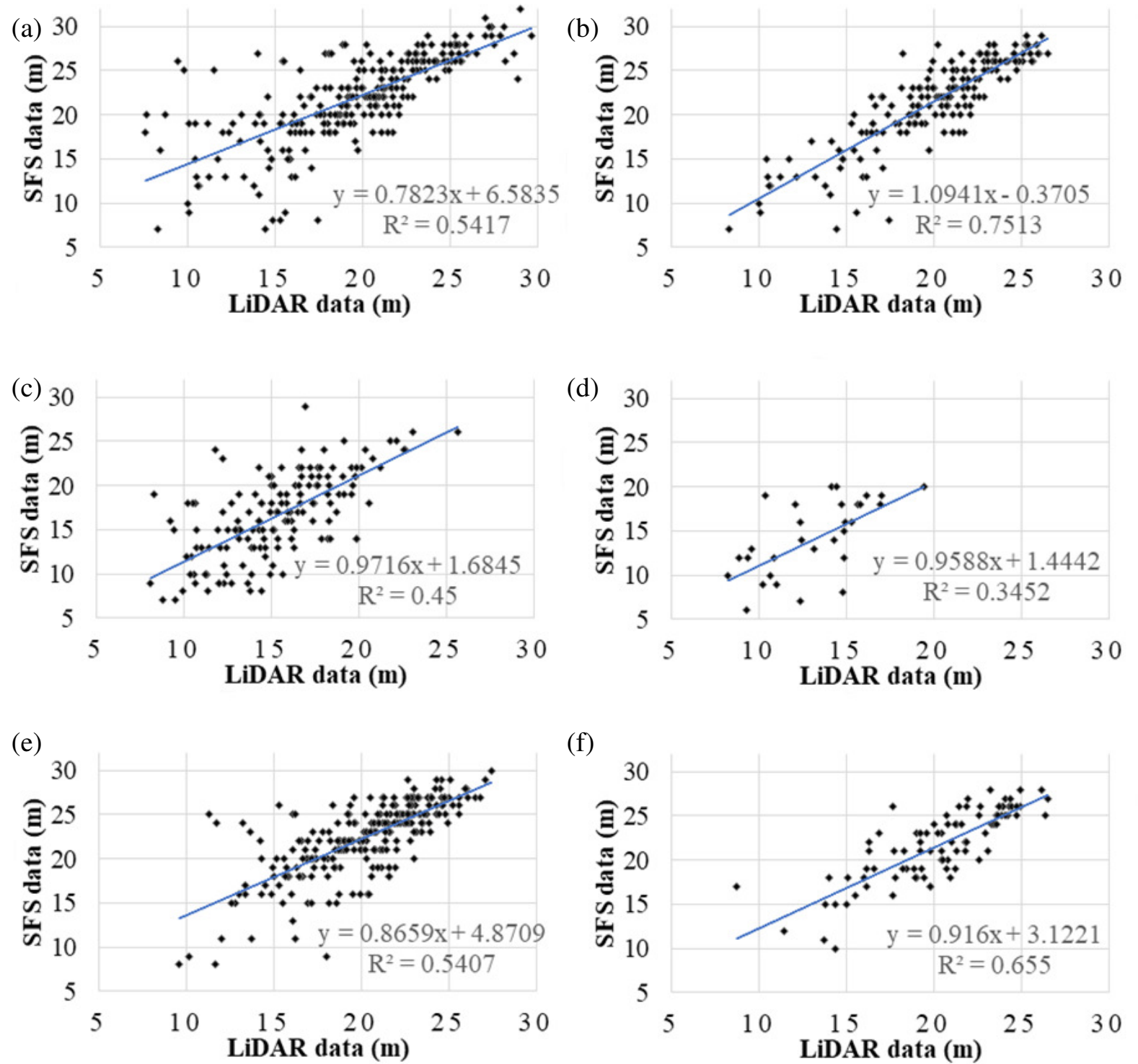

Fig. 3. Tree height comparison by forest growth conditions

The height of the dominant trees was also compared in the context of relief depressions (Fig. 4). Selected forest stands included area in local depressions with potentially hindered surface water runoff and the dominant tree species is scots pine. The values obtained from LiDAR data were compared. It has been observed that the trees growing in the depressions are up to $3 \mathrm{~m}$ shorter than the trees in the rest of the forest stand. The differences in the tree height are increasing as the stands grow older. 


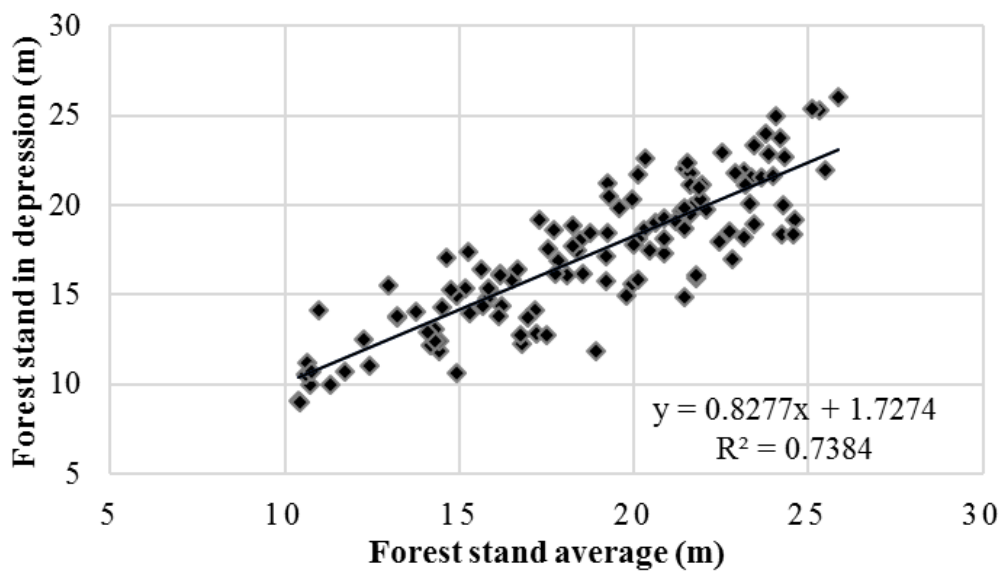

Fig. 4. Tree height comparison between relief depressions and rest of forest stand

The obtained results confirm that the method used in this study can be used to evaluate tree growth conditions and to estimate the tree height. The results show that the average dominant tree height from the LiDAR data is up to 2 meters lower than in the SFS database. Similar results have been observed in previous studies, when remote sensing data were compared with measurements from NFI plot plots [11].

\section{Conclusions}

1. LiDAR data can be used to determine the height of dominant trees, and the average tree height according to the measurements is up to 2 meters lower than in the SFS records.

2. The best match between the LiDAR data and the SFS database is observed for forest stands where the dominant tree species is scots pine, because it is an evergreen species with a relatively wide crown. There is high possibility that the pulse emitted by the laser scanner will be reflected from the tree top.

3. The results confirm that for trees growing in relief depressions the growth conditions are relatively poor comparing to the trees outside the depressions. The results show that the trees growing in the depressions are on average up to $3 \mathrm{~m}$ shorter.

\section{Acknowledgements}

The study is implemented within the scope of the memorandum between LSFRI Silava and Joint stock company "Latvia state forests" from 11.10.2011.

\section{References}

[1] Koch B., Kattenborn T., Straub C., Vauhkonen J. Forestry Applications of Airborne Laser Scanning. Maltamo M., Næsset E., Vauhkonen J., Eds. Springer: Dordrecht, The Netherland. 89. $5,2014$.

[2] Chen Q., Baldocchi D., Gong P., Kelly M. Isolating individual trees in a Savanna woodland using small footprint LiDAR data. Photogramm. Eng. Remote Sens., vol. 72. 2006, pp. 923-932.

[3] Ke Y., Quackenbush L.J. A review of methods for automatic individual tree crown detection and delineation from passive remote sensing. Int. J. Remote Sens., vol. 32, 2011, pp. 4725-4747.

[4] Zhen Z., Quackenbush L.J., Stehman S.V., Zhang L. Agent-based region growing for individual tree crown delineation from airborne laser scanning (ALS) data. Int. J. Remote Sens., vol. 36. 2015, pp. 1965-1993.

[5] Breidenbach J., Næsset E., Lien V., Gobakken T., \& Solberg S. Prediction of species specific forest inventory attributes using a nonparametric semi-individual tree crown approach based on fused airborne laser scanning and multispectral data. Remote Sensing of Environment, vol. 114(4), 2010, pp. 911-924.

[6] Koch B., Kattenborn T., Straub C., \& Vauhkonen J. Segmentation of Forest to Tree Objects. In Forestry Applications of Airborne Laser Scanning. Springer, 2016. pp. 89-112. 
[7] Zhen Z., Quackenbush L., \& Zhang L. Trends in Automatic Individual Tree Crown Detection and Delineation - Evolution of LiDAR Data. Remote Sensing, vol. 8(4), 2016, pp. 333.

[8] Koch, B., Heyder, U., \& Weinacker, H. (2006). Detection of Individual Tree Crowns in Airborne Lidar Data. Photogrammetric Engineering \& Remote Sensing, 72(4), 357-363.

[9] Hyyppä, J., Hyyppä, H., Inkinen, M., Engdahl, M., Linko, S., Zhu, Y.H. (2000). Accuracy comparison of various remote sensing data sources in the retrieval of forest stand attributes. For. Ecol. Management, 128, 109-120.

[10] Ivanovs, J., Lazdins, A. Evaluation of tree height and number of trees using LiDAR data. Engineering for rural development. 153, 2018, 1390-1394.

[11] Ivanovs J., Lupikis A. Identification of wet areas in forest using remote sensing data. Agronomy research, vol. 16(5), 2018, pp. 2049-2055.

[12] Wang L., Liu H. An efficient method for identifying and filling surface depressions in digital elevation models for hydrologic analysis and modelling. Int. J. Geogr. Inf. Sci., vol. 20, 2006, pp. 193-213.

[13] Mežalikums (Forest law). Latvijas republikas tiesibu akti, 2000. (In Latvian). [online] [18.03.2019]. Available at: https://likumi.lv/doc.php?id $=2825$ 